\title{
Enhancement of Decorative Flames and Gas Flow in Fireplace Design
}

\author{
Wei-Long Chen and Fang-Lin Chao
}

\begin{abstract}
This fireplace design is comprised of a gas furnace, a transparent barrier assembly, and a separator. The separator assembly is placed in the furnace structure, and an air chamber partitioned by a barrier corresponds to a combustion chamber. A space is formed between the outlet passage and the transparent glass. This breather chamber passage is connected to the combustion chamber, and functions as a cooling air channel for guiding air through the semi-enclosed space, which improves the temperature uniformity in the combustor. Ambient air is isolated from the house to ensure the safety of the fireplace. Guided airflow redirects a portion of high-temperature air. Downward heat circulation allows the accumulation of heat and enhances the efficiency of energy use.
\end{abstract}

Index Terms-Decorative flames, fireplace, gas flow, product design.

\section{INTRODUCTION}

Fireplace design aims to enhance usage, increase emotional value, and reduce environmental burden. Throughout history, fireplaces have attracted visual interest from people. A warm stove was a gathering place within the home. In recent years, the emotional design of a fireplace has become more important, providing a relaxed context [1] and improving the atmosphere of the room. Usually, an ornamental flame with a long flame path is aesthetically appealing to consumers.

Decorative fireplaces are popular with many people. At the same time, designers must pay attention to safety issues. When a traditional wood block burns, smoke can cause lower respiratory tract infections and other diseases [2]. Energy efficiency is also key to fireplace design. By closing the fireplace burner, the valve can prevent the bricks of the fireplace from melting. When the fire is turned on, the residual gas concentration increases. The arrangement of blocks that minimizes the spacing between them in a fixed kiln increases thermal efficiency [3]. In addition, a fireplace flame must provide a suitable fire pattern and color. Designers use many techniques to change the flame pattern or color: electromagnetically controlled flame patterns, coated ions on burners, or fake wood that ionizes at high temperatures. Artificial fires use water mist or swinging strips and additional light projection. However, the use of electric heating to simulate the flame color of traditional wood-burning fires is still the most popular.

An unvented fireplace is a significant source of indoor air

Manuscript received August 1;2018, revised September 19, 2019.

Authors are with the Department of Industrial Design, Chaoyang University of Technology, Taichung, 436, Taiwan (e-mail: flin@ cyut.edu.tw). pollutants. Single-family home exposure to emissions from unvented natural gas fireplaces may pose a risk to human health [4]. The efficiency of a chimney-free gas fireplace is high. However, exhaust gas and water vapor cannot be discharged to the outside, and indoor use causes an increase in humidity. Carbon monoxide is produced when the fuel is incompletely combusted, and nitrogen oxides are also produced at high temperatures. Carbon monoxide can combine with hemoglobin to form carboxyhemoglobin $\mathrm{COHb}$, leading to hypoxia in the heart and brain tissue.

Residential wood combustion has been identified as the dominant source of PM 10. PM 2.5 emissions have been reduced via appliance replacement and fuel changes. The magnitude of reductions has been calculated by population increment [5]. A recent analysis of CO distribution in homes with unvented gas fireplaces showed that $\mathrm{CO}$ dispersion occurred almost immediately upon operation. $\mathrm{CO}$ concentrations throughout the homes were found to be $70-80 \%$ of the level near the fireplaces. NO levels were similarly stable to $\mathrm{CO}$ and $\mathrm{CO}_{2}$ in an indoor environment, but $\mathrm{NO}_{2}$ and water vapor were removed from the air at much higher rates [6].

Our fireplace's simple design and small combustion scale grant it a lower technical difficulty than that of a chimney gas fireplace. Its flame and electronic control technology is equivalent to that of a straight-line gas fireplace, and it is compliant with gas interchangeability regulations. The chimney-free configuration imposes stricter requirements on harmful exhaust gases and must be combined with a sophisticated and reliable carbon monoxide detector and Oxygen Depletion System (ODS). This device ensures that the amount of carbon monoxide used is less than $20 \mathrm{ppm}$ for long periods of time.

\section{PREVIOUS DESIGN}

Previous fireplace designs can be found in the patent database. The air in the combustion chamber expands when it is heated, which causes air to exit the combustion chamber through the exhaust pipe. Meanwhile, the enclosed combustion chamber draws in outside air via negative pressure. The space between the high-temperature firebox and the outer chassis encourages an exchange of heat with the indoor air. Sometimes a fan or exchanger is required to enhance convection [7], so that the heating efficiency improves and increases the indoor temperature quickly.

A direct-vented fireplace intakes and exhausts air in a naturally balanced way, with the exhaust port and the intake port horizontally or vertically connected to the combustion chamber. The indoor air is completely isolated from the combustion chamber, which makes the direct-vented gas 
fireplace safe for home use. The inner pipe connecting the combustion chamber is adapted to exhaust the high-temperature waste air (Fig. 1). The exhaust gas temperature and velocity can be reduced to increase thermal efficiency by optimizing the gas-to-air mixture ratio.

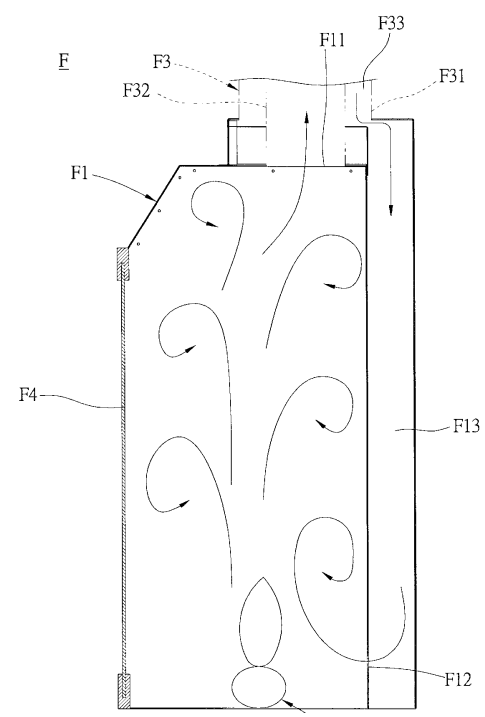

Fig. 1. Air goes up and exits the chamber through the exhaust pipe by stack effect [7].

US Patent no. 5016609 [8] describes a gas fireplace with glass on both sides. The design utilizes a diversion approach to enhance the exhaust flow. By increasing surface area at the top of the furnace, it increases heat exchange and improves thermal efficiency. "The top side wall plenum is connected to side wall plenums which exhaust heated room air along the glass side walls. The top wall of the fireplace is provided with a novel tapered combustion chamber which promotes and increases the velocity of burned combustion gases being exhausted and passed into the exhaust stack."

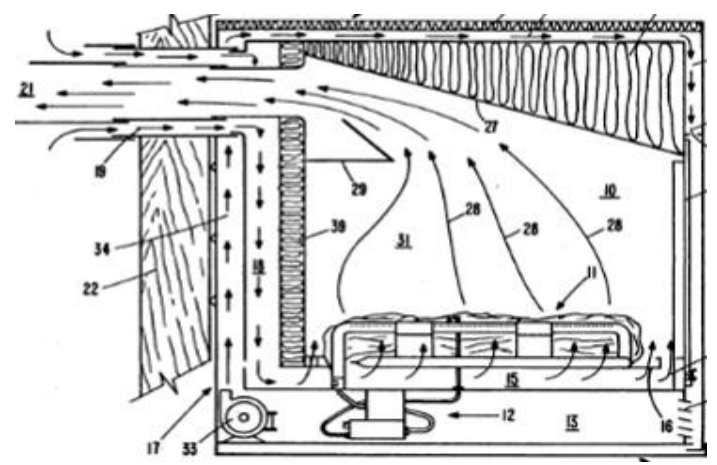

Fig. 2. Exhaust flow and heat exchanger arrangement of US Patent no.5016609.

A transparent glass cover is placed on the front side of the furnace for visualization. This allows the user to see and feel the radiant heat of the fireplace. The furnace has a barrier that isolates the user from high temperatures. In addition, the gas compound is close to the exterior wall, which reduces the space required for installation.

\section{DESIGN APPROACH}

\section{A. Non-quantitative Design Guidelines}

Fireplace re-design requires suitable structure and parameters for enhancing natural convection. The heat transfer caused by fluids is expressed with the following equation:

$$
Q_{w}=h\left(T_{w}-T_{f}\right)
$$

where $T_{w}$ and $T_{f}$ are the temperatures of the wall and the fluid respectively. The heat transfer coefficient $(h)$ depends on the kind of fluid, its flow state, and the shape of the object. The size and location of the vent opening are critical for flow guidance and the airflow mode. The diversion port can guide airflow in the ventilation path while reducing the occurrence of turbulence.

Several non-quantitative design guidelines collected through previous cases form the backbone of the redesigned fireplace concept. The design guidelines are as follows [9]:

- Carry out thermal characterization at the system level.

- Place different blowers in series or parallel unless the flow rates and head pressures in the system are balanced.

- Avoid obstructing coolant flow, guide flow employing splitters, and turning vanes.

- Maximize the radii of turn inflow passages (gradual turns, enlargements, and contractions).

\section{B. Design Contradictions}

However, a functional working direct-vented gas fireplace must meet several requirements and regulations: (1) High performance: since the intake and exhaust ports both lead outdoors, the efficiency of heat usage must comply with relevant laws and regulations. If either the exhaust temperature or the flow of the direct-vented gas fireplace gets too high, the performance of the stove will decrease. (2) Nearly complete combustion: the less carbon monoxide, hazardous material, and black smoke, the safer the product.

The fireplace design must visually mimic burning wood and produce an orange flame for aesthetic needs. A colorless or blue flame does not satisfy the viewer's visual needs. The fireplace must be able to adapt to a wide range of combustion scales to increase the range of applications. These conditions tend to conflict with each other. When thermal efficiency increases, the exhaust gas temperature and flow rate decrease. Insufficient intake air amount results in incomplete combustion and excessive carbon monoxide. However, complete combustion causes a colorless or blue flame. This flame cannot display an orange color. These contradictions in design require careful adjustment of the parameters of in-line fireplace structure.

\section{CAE and Design Procedure}

The CAE design procedure was chosen due to the complexity of the design (Fig. 3). The digital model was built with CATIA solid modeling package, which can be used to make a physical model.

The prototype model was used for measuring physical parameters. The measured data and simulation results were compared to adjust the simulation parameters. When the parameters were confirmed, we used the digital model to survey the possible settings.

As shown in Fig. 3, the design guides enabled us to choose the direction of concept generation. The flow calculations predicted the effect of geometric parameters. The results confirmed the product features by functional measurements 
to fulfill the checklist while remaining in compliance with regulations or requirements.

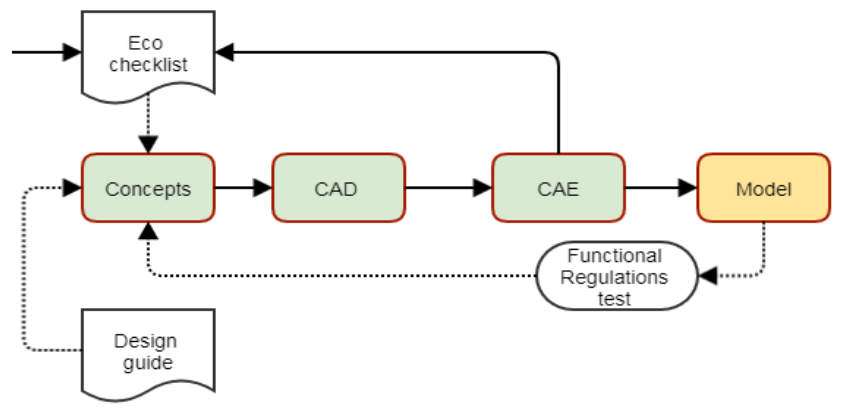

Fig. 3. The design flow of the fireplace.

\section{CONCEPTS OF FIREPLACE EFFICIENCY}

The fireplace design is based on the concept of gradual warm-up, allowing natural convection to move along the lower intake zone. Upward moving air then flows toward the baffle (58, Fig. 4) above the burner. Since the baffle causes airflow to move slowly in a pre-set direction, it forms a partial laminar flow. At the same time, as airflow moves upward, another portion of the baffle adjusts the flow rate. This flow resistance maintains the flow in proper combustion conditions.

\section{A. Laminar and Stability}

Two steady flow plates (60) located are located on either side of the gas supply. One end of each of the flow plates is fixed to the fireplace structure. Two stop walls protrude from a surface of the board in the combustion chamber. Flame in the burner generates hot air, which is limited between the plates (542) before it moves toward the exhaust port. The plates located further from the chamber are inserted into corresponding slots by separators on opposite sides [9], [10].

A translucent shield (52) is installed on the side of the firebox (50). The main body has an outer shell that engages with a burner near the main inlet. The main body either exactly covers the window or at least includes a side of the window near the bottom portion. The flame burning in the firebox is therefore visible through the main structure.

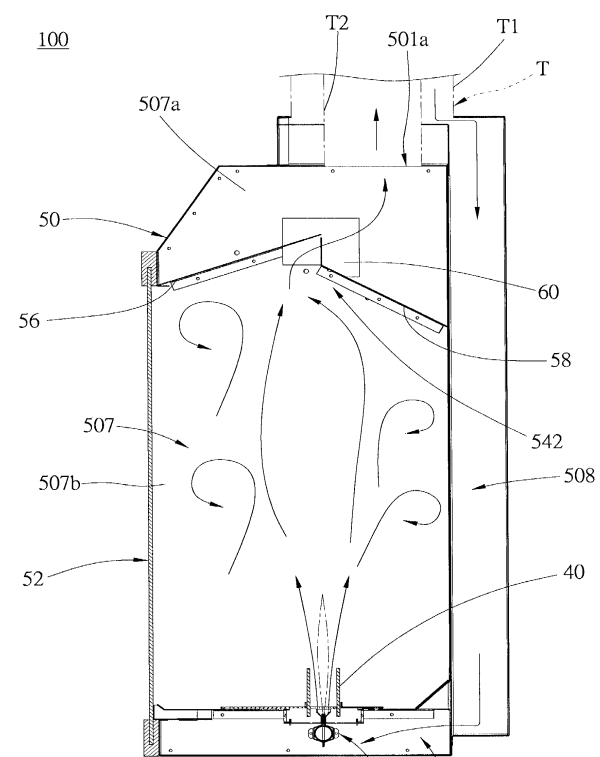

Fig. 4. Proposed structure to maintain laminar flow [9], [10].

\section{B. Energy Conservation}

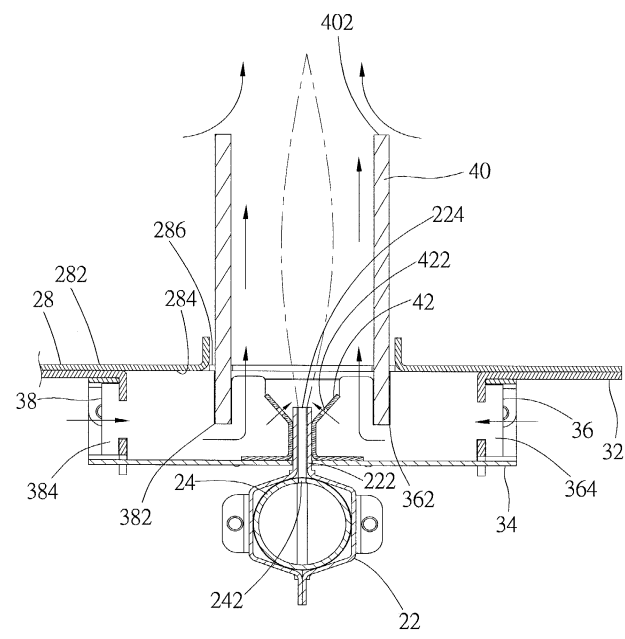

Fig. 5. Section view of the burner shown a detail of the guide vane (where arrows indicate the flow directions) [9], [10].

As shown in Fig. 5, the gas supply passage of the supporting model also contains guide members $(36,38)$ to distribute the air in the gas supply passage. This design prevents the accumulation of hot air in the exhaust passage. Multiple splitter plates are placed vertically along the guide plate (40) and provide more even airflow. With decreased turbulence during airflow, the configuration prevents accumulation of waste gases. The guided airflow plate effectively increases the range of the laminar flame via the Coandă effect [11].

The flow guide device includes a laterally provided separator (28), a holder, several first separating plates (36), several second separating plates (38), and two stop plates (40). The separator has a top surface (282), a bottom surface (284), and an opening (286) going through the upper and the bottom surfaces. The opening is long, with its major axial direction parallel to an axial direction of the combustor. The holder (30) is provided on the bottom surface of the separator (28).

\section{Simulation, Prototyping, and Measurement}

A simulation was conducted with finite-difference numerical analysis to help to understand the flow field distribution. Data quality and simulation duration increase significantly with time step size. A reasonable balance is necessary for simplified geometric discretization and time duration.

The measured physical parameters were confirmed by the modeling settings. A one-to-one scale prototype was produced for the combustion test.

\section{A. Simulation}

A simplified 3D CAD model with guided vanes and outlet boundaries is shown in Fig. 6; the analysis results are displayed in Fig. 7. We found that the airflow gradually moved upward along the baffle, and the velocity was within the laminar flow range. The temperature of the central viable flame region was $631-750^{\circ} \mathrm{K}$. This laminar flow supported complete combustion and reduced the chances of carbon monoxide production. 


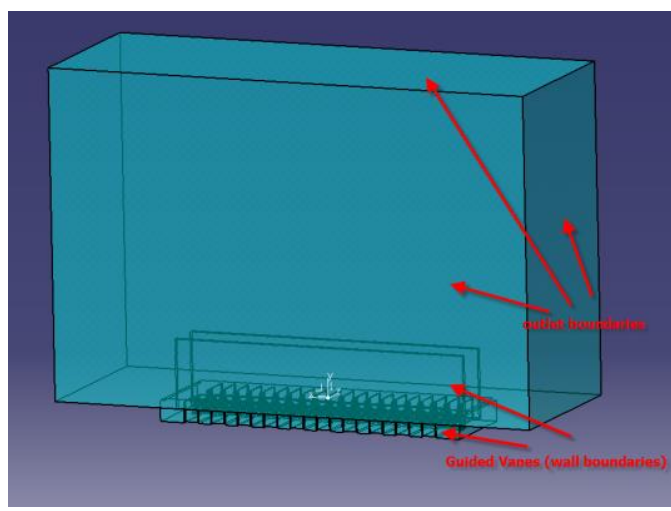

Fig. 6. Simplified 3D simulation model with guided vanes (wall boundaries) and outlet boundaries.

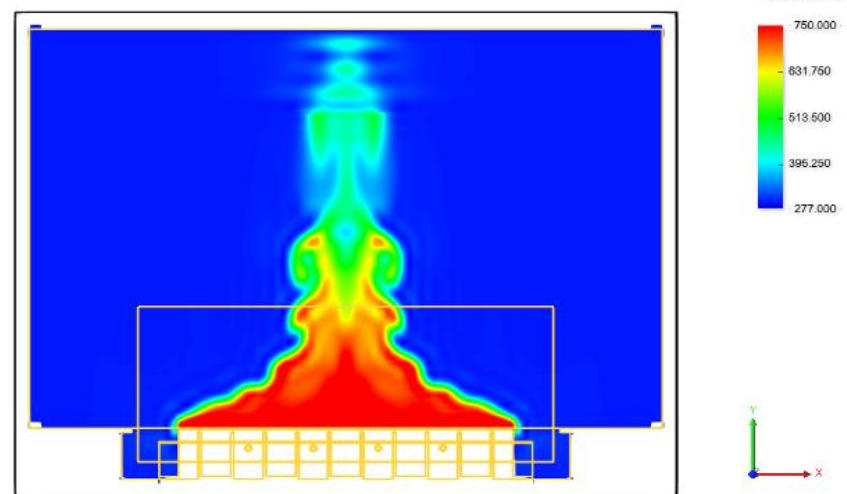

Fig. 7. Flow field and flame results. The large rectangle is the guide region, the small square area below is the gas mixing zone.

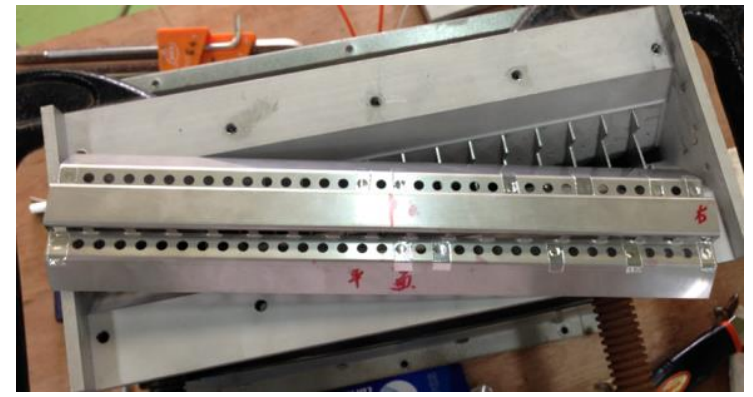

(a)

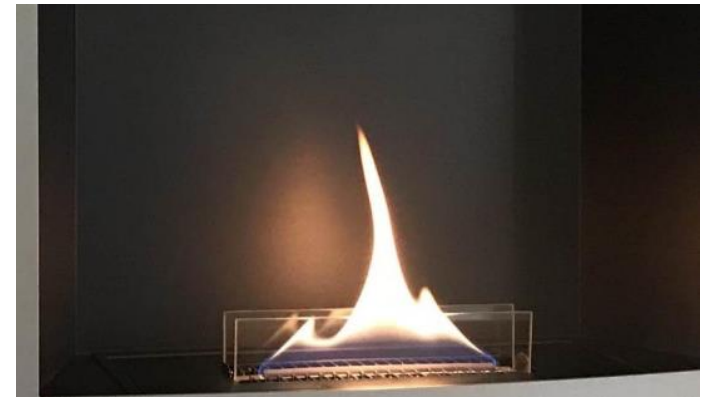

(b)

Fig. 8. Prototype of gas fireplace for functional measurement and visual verification of decorative flames. (a) Gas mixing chamber elements. The prototype mixing chamber can independently adjust the mouth velocity and concentration of the 17 fire vents to show the appropriate decorative flame.

(b) Demonstration of typical flame shaped like a waterfall.

\section{B. Prototyping and Measurement}

A prototype was produced to verify the ability of the proposed structure to produce an ornamental flame (Fig. 8(a)). The length of the plate was $20 \mathrm{~cm}$. The primary structure was built from steel, which has excellent structural strength but high thermal conductivity. The heat generated at the combustion source was transmitted to the exterior of the fireplace frame via conduction, convection, and radiation. The area that the user touches during operation needed to be maintained at an appropriate temperature range to reduce the risk of injury.

Sensors were utilized to measure the temperature of significant areas of concern along the flow path. By measuring the temperature of the structure, the designer was able to compare the numerical simulation results to adjust the boundary condition settings (Fig. 8(b)).

\section{Checklist}

In the qualitative evaluation, some significant keywords for improvement were low-impact materials, reduction of material usage, optimization, and reduction of environmental impact during use. Five criteria were chosen to analyze the prior and redesigned models, namely functional need, low impact material, few manufacturing steps, low energy consumption, and safety.

A radar chart allowed us to integrate other factors beyond main function. Easy-to-obtain materials and simplified structural design reduce the difficulty of manufacturing; low energy consumption and product safety maintenance are also user-assessed factors. The radar diagram shown in Fig. 9 indicates that the performance of the redesigned model is qualitatively better than the previous product (especially in function, security, and energy use).

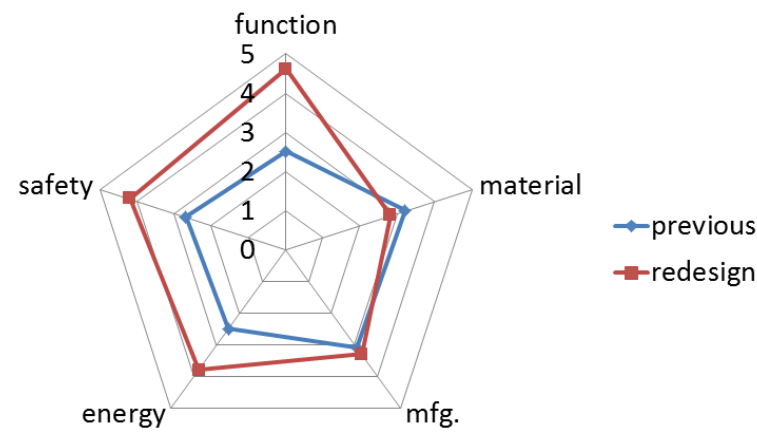

Fig. 9. Qualitative performance of re-design fireplace (Re-design and prior art), which assessed by engineer and marketing expert

Airflow guidance is usually controlled by adding an electric fan, which is efficient but consumes additional energy. When the fan fails, it will also cause the primary system to malfunction. A design with no moving parts results in a lower failure rate and decreased maintenance. Major materials are recyclable to reduce environmental impact. The design guidelines related to natural convection of the combustion phenomenon and the CAE results were analyzed during this design process to select the proper "design options." Through the prototype measurement, we were able to verify the simulation and energy efficiency data.

The redesign uses a similar amount of material and does not use an active device (blower) while still providing useful natural convection. The model does not result in incomplete combustion, which is a significant increase in product safety.

\section{CONCLUSIONS}

A combined qualitative and CAE design process proposal for fireplace redesign results in a model that serves its 
function and increases energy efficiency during use. Through a digital model, we were able to verify the simulation parameters and chose the proper settings to achieve design goals.

Gas flow guide element and fireplace comprises a gas furnace, a transparent mask assembly, and a separator which is placed along the outlet passage. This arrangement allows a higher air temperature in the combustion chamber. This redesign provides circulation and preserves the accumulation of heat in the furnace to enhance energy use. Further benefits of the redesign are:

(1) Precise control of the combustion of the second mixture with the diversion design. The oxygen concentration was greatly reduced, and the combustion efficiency was improved without being disturbed by the exhaust gas of the combustion chamber.

(2) The guided airflow design utilizes the Coandă effect to increase the range of laminar flame combustion effectively. Prototype experiments have found that reducing the generation of turbulent flow around the flame prevents excessive aeration, reduces colorless flame, and produces fewer harmful nitrides.

\section{REFERENCES}

[1] Fireplace. [Online]. Available: https://en.wikipedia.org/wiki/Fireplace

[2] D. Kehler and H. Curic, "Identified as young couple killed in Kurrajong cabin," The Sydney Morning Herald, June 9, 2015.

[3] J. E. Houck, P. E. Tiegs, J. Crouch, and C. Keithley, "The PM2. 5 reduction potential of new technology home heating appliances and fuels," in Proc. the Air and Waste Management, US Environmental Protection Agency and US Department of Energy International Specialty Conference, 1998, vol. 5, pp. 28-30.

[4] G. M. Martínez-González and H. Jiménez-Islas, "Experimental study of the firing of red clay bricks using liquefied petroleum gas," Journal of Scientific and Industrial Research, 2014.
[5] P. W. Francisco, J. R. Gordon, and B. Rose, "Measured concentrations of combustion gases from the use of unvented gas fireplaces," Indoor Air, vol. 20 no. 5, pp. 370-379, 2010

[6] S. J. Dutton, M. P. Hannigan, and S. L. Miller, "Indoor pollutant levels from the use of unvented natural gas fireplaces in Boulder," Colorado. Journal of the Air \& Waste Management Association, vol. 51, no. 12 pp. 1654-1661, 2001.

[7] R. J. Shimek and D. C. Shimek, "Direct-vented gas fireplace," U.S Patent 4,793,322., December 27. 1988.

[8] R. J. Shimek and D. C. Shimek, and J. F. Wolf, "Direct vented multi glass side fireplace," U.S. Patent 5,076,254, December 31. 1991.

[9] W. L. Chen, "Gas fireplace and its flow guiding element" U.S. Patent 2017/0009998 A1 2013/0011800 A1, 2015.

[10] W. L. Chen, "Gas fireplace and its flow guiding elements," Taiwan patent application no. 104122332, 2015.

[11] Coandă effect. (2019). [Online]. Available: https://en.wikipedia.org/wiki/Coand\%C4\%83_effect

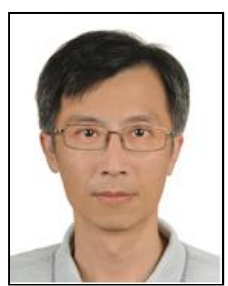

Wei-Long Chen received his Ph.D. degree in aerospace engineering from the University of Oklahoma. He was a researcher of MSC software; he also served as a consultant in several companies such as Pro-Iroda, Grand Mate and Aerospace Institute.

$\mathrm{He}$ joined the National Center for High-Performance Computing, Hsinchu, Taiwan Since September 1999, he has been an associate professor with the Department of Industrial Design at Chaoyang University of Technology, Taichung, Taiwan. His research interests include CAE and product development.

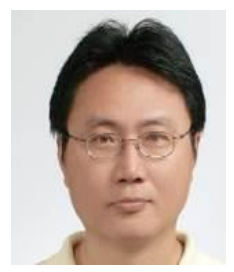

Fang-Lin Chao received his $\mathrm{Ph} . \mathrm{D}$. degree in electrical engineering from National Taiwan University. He joined the Electronics Research and Service Organization, Industrial Technology Research Institute, Hsinchu, Taiwan, in 1982. In 1994, he was named associate professor at the Da-Yeh Institute of Technology and Chaoyang University of Technology. His research interests include eco-design and design integration. 